\title{
IOANNIS CALVINI, Opera Exegetica. Volumen VI. Praelectiones in librum prophetiarum Jeremiae
}

\section{Michele Mastroianni}

\section{OpenEdition}

\section{Journals}

\section{Edizione digitale}

URL: http://journals.openedition.org/studifrancesi/16281

DOI: 10.4000/studifrancesi.16281

ISSN: 2421-5856

\section{Editore}

Rosenberg \& Sellier

\section{Edizione cartacea}

Data di pubblicazione: 1 juillet 2019

Paginazione: 146

ISSN: 0039-2944

\section{Notizia bibliografica digitale}

Michele Mastroianni, «IOANnIS calvinI, Opera Exegetica. Volumen VI. Praelectiones in librum prophetiarum Jeremiae», Studi Francesi [Online], 187 (LXIII | I) | 2019, online dal 01 juin 2019, consultato il 25 janvier 2021. URL: http://journals.openedition.org/studifrancesi/16281 ; DOI: https://doi.org/10.4000/ studifrancesi. 16281

Questo documento è stato generato automaticamente il 25 janvier 2021.

\section{(c) (i) (9)}

Studi Francesi è distribuita con Licenza Creative Commons Attribuzione - Non commerciale - Non opere derivate 4.0 Internazionale. 


\title{
IOANNIS CALVINI, Opera Exegetica. Volumen VI. Praelectiones in librum prophetiarum Jeremiae
}

\author{
Michele Mastroianni
}

\section{NOTIZIA}

IOANNIS CALVINI, Opera Exegetica. Volumen VI. Praelectiones in librum prophetiarum Jeremiae, t. I-II, edidit N. Gueunier, cooperante M. Engammare, Genève, Droz, 2016, t. I 1000 pp.; t. II $1891 \mathrm{pp}$.

1 Così come viene sottolineato dal curatore dei due volumi in apertura della ricca $\mathrm{e}$ dettagliata introduzione al t. I, le Praelectiones rimandano a un genere di letteratura edificante che si trova a mezza strada fra il sermone e il commento scritto. Genere didattico strettamente legato alla predicazione, diversamente da quanto accade per $\mathrm{i}$ sermoni, le Praelectiones divergono dai commentaires, poiché esse sono oggetto di trasmissione orale prima ancora di riverberarsi in scrittura, quindi in testo. Nel caso specifico delle Praelectiones - come ricorda N. Guenier - «Calvino dava tre lezioni a settimana a Ginevra, a partire dal 1549. Ciascuna di esse durava un'ora all'“Auditoire", situato nei pressi della chiesa Saint-Pierre. Il pubblico era composto da studenti, il che distingue le Praelectiones dalle Congrégations, specie di seminari biblici che riunivano pastori, soprattutto di città, e che erano tenuti in francese, mentre le lezioni si facevano in latino, in generale essendo gli studenti sufficientemente istruiti per comprendere anche le numerose citazioni in ebraico e in greco» (p. Ix).

2 Se Calvino comincia a elaborare le sue lezioni a partire dal 1549, le Praelectiones in librum prophetiarum Jeremiae si succedono nel tempo, dall'inizio del 1559 al 9 gennaio 1563, presentandosi come una lettura continuata del testo biblico: «Calvino leggeva ogni versetto, prima in ebraico poi lo traduceva in latino, intercalandovi (diversamente dai commenti scritti) delle "glosse", presentate nel testo scritto in corsivo. Queste 
consistono principalmente in spiegazioni linguistiche d'un termine ebraico o in spiegazioni critiche di un'altra traduzione latina» (p. Ix). Come evidenzia M. Engammare, le Praelectiones sono certamente un "prodotto dell'oralità» il che è visibile e riscontrabile attraverso il numero cospicuo di pronomi e forme verbali in prima persona, del singolare come del plurale (ego, nos, nobis, fateor, inquam, non dubito, dicimus ecc.). Parallelamente, la presenza di un pubblico è manifesta, anche se in misura minore, attraverso l'uso di pronomi come vos e vobis e di forme verbali alla seconda persona plurale. Tuttavia «è soprattutto attraverso le strutture sintattiche affermative o negative, imperative e interrogative che il professore interpella il suo pubblico, nella fattispecie bombardandolo letteralmente di domande retoriche, che sono quasi immediatamente seguite da risposte: «cur ergo dicit? [...] «Respondeo», oppure «facilis est solutio» (p. XI). Non solo. Un uso abbondante di proverbi e locuzioni tanto in latino quanto in francese confermano il tono colloquiale delle lezioni. Se a livello di forma sono questi i tratti retorici distintivi delle Praelectiones, a livello di contenuto i grandi temi trattati concernono essenzialmente la giustificazione per sola grazia, la gratuità della grazia, la contestazione del libero arbitrio, la critica della 'cerimonie' papali, degli errori commessi dagli anabattisti ecc. Senza però dimenticare il principio della Sola Scriptura, con il quale Calvino aderisce a pieno titolo alla dottrina luterana, facendone un asse portante della sua ermeneutica. Di fatto, solo la Scrittura è ritenuta mezzo sine qua non è possibile conoscere Dio e accedere alla conoscenza di Dio. Affinché ciò fosse possibile era necessario - ribadisce con chiarezza il curatore - porsi il problema fondamentale del discernimento dei «falsi profeti». Ed è proprio questo uno dei temi fondamentali delle Praelectiones «che mostrano la lotta costante del vero profeta Geremia contro i falsi profeti o pseudo profeti, termini sinonimici le cui occorrenze sono innumerevoli» (p. xviII). Ora, come "praticare tale discernimento dinanzi alla scrittura profetica» - si domanda Gueunier - se non col diffidare anzitutto dal «procedere per associazioni di idee o di parole, scoglio questo frequente del modo di indagare del metodo allegorico? [...] al contrario è necessario mettere in opera un procedimento sintagmatico, cercando in ciascuna delle occorrenze e a partire dal suo contesto lo scopus che essa si prefissa». In questo senso - conclude l'editore - lo scopus si definisce grazie a un processo tipologico. «Si tratta di reperire i loci testuali in cui un personaggio o un avvenimento dell'Antico Testamento rimanda alla figura o alla storia di Gesù Cristo» (p. xIX). Partendo dal presupposto fondatore delle Praelectiones, quello cioè di docere, risulta indispensabile operare una distinzione fra le tre tecniche fondamentali che presiedono a tale insegnamento; tecniche quali l'expositio, l'argumentatio e l'exhortatio.

3 Con questa ottima edizione, corredata da un apparato critico puntuale e utilissimo si dispone ora di uno strumento di riflessione e di lavoro filologicamente solido e indispensabile per la storia della spiritualità europea fra Riforma e Controriforma. 